\title{
Necessidades formativas de professores de matemática para o uso de tecnologias digitais: uma análise curricular segundo princípios habermasianos $^{1}$
}

Eduardo Cortez Guimarães eduardocortez34@gmail.com 0000-0002-6622-7510 Universidade Estadual Paulista, llha Solteira, São Paulo, Brasil.

Thais Paschoal Postingue thaisppostingue@gmail.com 0000-0002-9849-6870 Universidade Estadual Paulista, Bauru, São Paulo, Brasil.

Deise Aparecida Peralta deise.peralta@unesp.br 0000-0002-5146-058X Universidade Estadual Paulista, Ilha Solteira, São Paulo, Brasil.

\section{RESUMO}

Esta pesquisa identifica, em Projetos Políticos Pedagógicos de curso de licenciatura em matemática, de universidades públicas do estado de São Paulo (UNESP, UNICAMP, USP), características da formação de futuros professores para o uso de tecnologias digitais no ensino de conteúdos curriculares. Guiando-se pela análise documental qualitativa, constitui-se informações acerca da organização curricular dos cursos de licenciatura em matemática, das características dos currículos destes cursos em relação a formação para o uso de tecnologias digitais em sala de aula, da predominância da carga horária das disciplinas relacionadas aos conhecimentos específicos em matemática em detrimento aos conhecimentos relativos aos fundamentos da educação, da formação para docência e de tecnologias digitais como recurso à prática pedagógica.
\end{abstract}

PALAVRAS-CHAVE: Formação de Professores. Currículo. Licenciatura em Matemática. Tecnologias Digitais. 


\section{INTRODUÇÃO}

Em pesquisa realizada anteriormente (PERALTA; GUIMARÃES, 2018) investigou-se a possibilidade da robótica educacional como constituinte de prática pedagógica interdisciplinar alternativa ao ensino tradicional de conteúdos curriculares. Na referida investigação evidenciou-se que a robótica educacional tem o potencial de tornar o estudante produtor, e não apenas consumidor de tecnologia digital, e o professor protagonista em processos de (re)construção da própria prática. A partir dos resultados vislumbrou-se a possibilidade da robótica na escola se apresentar, não como mais uma ação de instrumentação, mas como uma oportunidade de interação com a tecnologia numa relação de construção e reconstrução de práticas. Porém, os professores participantes da pesquisa relataram que um dos desafios a serem enfrentados, em processos de implantação de projetos de tecnologia digital como prática pedagógica, é a formação docente.

Dentre esses resultados há relatos de professores afirmando não se sentirem preparados para assumirem tecnologias digitais como constituintes de práticas docentes se não forem formados, adequadamente, para tal. Diante disso, e considerando as tecnologias digitais como suporte ao conhecimento na contemporaneidade, parece pertinente defender que ser formado para o uso de tecnologias digitais se faz uma necessidade e deveria ser contemplado nos cursos de formação inicial de professores. Nesse sentido, e em consonância com os dados da referida pesquisa, a investigação a ser relatada neste artigo objetivou analisar, segundo os princípios habermasianos, a organização de currículos descritos nos Projetos Pedagógicos de Cursos de Licenciatura em Matemática, desenvolvidos em três universidades estaduais paulistas ${ }^{2}$ (UNESP, USP, UNICAMP), e identificar aspectos que privilegiem a formação dos futuros professores para o uso de tecnologias digitais em suas futuras práticas profissionais.

\section{TECNOLOGIAS DIGITAIS E AS NECESSIDADES FORMATIVAS DE PROFESSORES}

Em provável origem na Grécia antiga, o vocábulo tecnologia nos remete ao conhecimento que advém da relação entre ciência e técnica num movimento de interação que permite a contínua produção científica e consequente aprimoramento da técnica. Talvez faça sentido dizer que "tecnologia envolve um conjunto organizado e sistematizado de diferentes conhecimentos científicos, empíricos e até intuitivos voltados para um processo de aplicação na produção e na comercialização de bens e serviços" (GRINSPUN, 1999, p.49).

O domínio de uma tecnologia pressupõe, e isso tem justificado investimentos em prol de seu desenvolvimento, aumento da eficiência da ação humana no mundo social, principalmente, na dimensão produtiva. Diz-se isso pois, "a tecnologia revela o modo de proceder do homem para com a natureza, o processo imediato de produção de sua vida social e as concepções mentais que delas decorrem" (MARX, 1988, p. 425).

Tecnologia em educação, de forma geral, refere-se à ação educativa associada a uma técnica apoiada em uma ciência. Todavia, diante do avanço das chamadas novas tecnologias, a expressão tecnologia educacional tem sido bastante utilizada e tem se relacionado, com muita frequência, a recursos tecnológicos que, característicos de uma categoria específica de tecnologia: a digital, que podem ser empregados no dia a dia nas escolas. 
A tecnologia digital, na sociedade atual, não se faz mais uma tecnologia reservada a especialistas, sendo que saber operá-la constitui-se em condição necessária para participação na cultura ocidental contemporânea. Não há como fechar-se aos acontecimentos e, ainda que de maneira incipiente, é preciso considerar essas mudanças no debate e na prática educacional. Talvez seja necessário considerar a pertinência de formar professores para a fluência tecnológica para que tenham acesso ao domínio da linguagem digital. A concepção de tecnologia é uma concepção política, na medida em que a transformação do mundo natural e do mundo social impacta na do homem, e em que os produtos das práticas humanas impactam nos mundos natural e social e a elas retornam. Entretanto, parece incontestável que o desenvolvimento tecnológico fomenta avanços ou retrocessos no desenvolvimento de uma sociedade. Entretanto, se a tecnologia transforma a produção material, pode [ela, a tecnologia] ter o poder de definir uma cultura inteira, projetando uma totalidade histórica. (HABERMAS, 2006).

Uma educação com tecnologia digital em consonância com os conceitos de Emancipação ${ }^{3}$ (HABERMAS, 2006) e Fluência Tecnológica (PAPERT; RESNICK, 1995) se contrapõe a uma educação tecnicista, pois não se reduz à capacitação técnica. Nesse contexto é inegável o papel determinante do professor que, para tanto, necessita de formação.

Nos últimos dos últimos anos, os paradigmas de formação passaram a ser questionados nos debates sobre a formação docente em termos de sua efetiva contribuição para a mudança qualitativa da prática pedagógica do professor. (PERALTA, 2012; POSTINGUE; PERALTA, 2018). Dessa forma, foi se delineando, no atual cenário educacional, um movimento de buscas, de reflexões e de pesquisas voltadas à construção de novos caminhos para a formação inicial e contínua, no bojo do qual o discurso em defesa do que a literatura tem denominado necessidades formativas, entendida como uma modalidade que busca ir ao encontro das expectativas, interesses e motivações dos professores, se fortalece e se justifica.

Silva $(2000$, p. 23) define o termo formação como o ato de "[...] dar o ser e a forma, bem como organizar e estabelecer", o que implica tanto uma dimensão relacionada à transmissão de conhecimentos (o saber e o saber-fazer), quanto uma dimensão de transmissão de valores (o saber-ser). Assim o sendo, formação perpassa, necessariamente, um caráter contextual que pode ser expresso no entrelaçamento dos processos formativos às experiências de quem se forma. (PERALTA, 2019). Assim, em conformidade com os pressupostos subjacentes à abordagem de formação na perspectiva de processo permanente de desenvolvimento profissional, ou seja, o processo de aprender a ensinar que se prolonga por toda a trajetória do docente,

\footnotetext{
a análise de necessidades se faz necessária e não se refere simplesmente a um processo de identificação de necessidades formativas, concebidas como as leis necessárias da formação às quais se submeteriam fatalmente formandos e formadores, mas, como as finalidades que cada um atualiza ou projeta num dado contexto, em função das representações que constrói do real e da sua relação com ele (RODRIGUES, 2006, p. 102).
}

Ainda segundo Rodrigues (2006), podemos nos referir ao já exposto de outro modo: não se trata de descobrir um dado objeto - necessidades de formação - 
como uma existência objetiva e evidenciada, independentemente, de quem o conhece, mas de construir (eventualmente ajudar a construir) um projeto necessidades de formação - que se elabora na relação interativa sujeito - contexto - objeto instrumentos usados nessa interação. Neste artigo a expressão necessidades formativas não se refere a necessidades objetivas, evidentes, como se elas já existissem inscritas a priori, bastando serem descobertas. As necessidades são representações da realidade construídas em determinadas situações e por determinadas pessoas. O que aparenta a existência de necessidades objetivas pode ser "o fato de algumas necessidades serem sentidas ou percebidas por um grande número de pessoas, o que lhes outorga uma intensa força coletiva." (DI GIORGI et al., 2011).

[...] continuamos, a saber, e a sentir que há necessidades, que há "coisas" que nos fazem falta, de que precisamos, que gostaríamos de ter, ou que, se fossem "possuídas", contribuiriam para a resolução de alguns problemas profissionais, ainda que o grau de necessidade e a sua força impositiva possam variar muito. [...] a necessidade de formação é [portanto] o que, sendo percebido como fazendo falta para o exercício profissional, é percebido como podendo ser obtido a partir de um processo de formação [...] (RODRIGUES, 2006, p. 104).

Neste artigo a expressão necessidade(s) formativa(s) é usada objetivando fazer referência ao que faz falta, ou ainda, e talvez melhor, ao que é entendido como fazendo falta, evocando a percepção subjetiva e contextualizada dos futuros professores e incluindo, ainda, desejos e expectativas em relação ao ser formado para o uso de tecnologias digitais no ensino que deveria ser previsto nos currículos dos cursos de licenciatura em matemática.

\section{CURRÍCULO E EDUCAÇÃO MATEMÁTICA}

Quando a indagação sobre o que é currículo surge, se faz necessária grande reflexão acerca do conceito e de tudo que ele envolve. Currículo é mais que o ideário de grade curricular, ou seja, não se limita a um documento que contém componentes a serem rigorosamente atendidos para aprovação e finalização de algum curso (LOPES, 2011). Uma discussão sobre o conceito de currículo acarreta uma incursão epistemológica, onde se procura entender as teorias de currículos, sua evolução e suas diferentes facetas.

Em Pacheco (2016), currículo é descrito itinerário formativo, com uma identidade cultural, histórica e socialmente contextualizada. Dessa forma, pode-se analisar o currículo como sendo um elemento cultural, socialmente construído (GUIMARÃES, 2014). Em posse de tais definições percebe-se que o currículo não é algo imutável, pelo contrário, apresenta inúmeras características que mudam, concomitantemente, à época e sociedade em que está inserido.

Segundo Silva (2001), o currículo está inextricavelmente, centralmente, vitalmente, envolvido naquilo que somos, naquilo que nos tornamos: na nossa identificação, na nossa subjetividade. Para esse autor, além de uma questão de conhecimento, o currículo tem a ver com identidade.

Não é difícil aceitar que diferentes povos, em diferentes épocas apresentam culturas diferentes. Assim sendo, as prioridades, as ideologias e a classe dominante mudam de acordo com o lugar e o tempo. Em concordância com Pacheco (2016) e 
Silva (2001), conclui-se que currículo se relaciona a, e assume muitas, concepções, tornando-se assim objeto de estudos e divisor de opiniões. Como consequência desses diferentes pontos de vista surgem as teorias de currículo que buscam interpretar o currículo sob diferentes percepções e em múltiplos contextos, além de resgatar as influências históricas, políticas e da sociedade em que foi criado.

Especificamente, em relação ao binômio currículo e matemática, Pires (2008), defende que na segunda metade do século XX, três períodos marcantes podem ser identificados: o primeiro, caracterizado pela influência do Movimento Matemática Moderna (de 1965 a 1980); o segundo, caracterizado por reformas que buscavam se contrapor ao ideário do Movimento Matemática Moderna (de 1980 a 1994) e lideradas por Secretarias Estaduais e Municipais de Ensino; o terceiro, organizado em nível nacional e consubstanciado num documento divulgado ao conjunto das escolas brasileiras, denominado Parâmetros Curriculares Nacionais (a partir de 1995). Esse movimento não trouxe muitos benefícios aos estudantes, pois, muitas vezes, o conteúdo não estava de acordo com a idade dos estudantes e os professores não tinham formação suficiente para se adequarem. Em contrapartida, contribuiu para Educação Matemática ao passo que novos grupos de estudo/pesquisa foram criados com o intuito de melhorar o processo ensinoaprendizagem dos estudantes.

Segundo Pires (2008),

\begin{abstract}
De todo modo, há que se contabilizar como saldo positivo nesse período, o despertar para a existência de problemas ligados ao ensino de Matemática, para a necessidade de compreender a gênese de conceitos como os de número e do espaço e de sua construção pelas crianças, impulsionada pelos trabalhos de Piaget e seus seguidores e para a busca de estratégias e recursos didáticos que pudessem melhorar a aprendizagem dos alunos em Matemática (PIRES, 2008, p. 20-21).
\end{abstract}

Analisando esse primeiro momento percebe-se uma concordância com a afirmação de Dowling (1998 apud Miguel, 2005), que fala que a Educação Matemática é envolvida pela ideologia do individualismo e possui suas raízes na matemática, na psicologia e na prática cotidiana de sala de aula.

Com o declínio do Movimento da Matemática Moderna e o fim da ditadura militar, que se implantou no Brasil em 1964, novas propostas inspiradas, no ideal de uma escola democrática, surgiram (PIRES, 2008). Esse período foi marcado, pelos debates, discussões e movimentos criados com intuito de refazer as propostas de ensino ao ensino básico. Contudo, os currículos mudavam muito de uma região para a outra, sendo que as regiões que possuíam grande acesso a informação e aos debates da época possuíam currículos vanguardistas, fato que acontecia de forma oposta nas regiões mais escassas de informações e estudos na área, onde os currículos chegavam a ser meras réplicas de listas de conteúdos.

A partir dessa heterogeneidade curricular no cenário nacional, mesmo sofrendo forte crítica à centralização e à padronização do currículo, foram criados os Parâmetros Curriculares Nacionais (PCN), iniciando o terceiro momento mencionado. Percebe-se então que o currículo para a Educação Básica mudou, e muda constantemente, mediante o momento em que nos situamos. A formação de professores é diretamente influenciada por essas mudanças, sendo que muitas vezes não acompanha de forma síncrona as transformações que ocorrem nas 
escolas, o que pode gerar uma insegurança nos professores que se fecham para o novo.

\section{A FORMAÇÃO DE LICENCIADOS NO BRASIL E A TEORIA DA AÇÃO COMUNICATIVA (TAC)}

Em virtude da Lei no 5.692/71, os cursos de licenciatura no Brasil seguiram o modelo $3+1$. Nesse paradigma há ênfase em disciplinas de natureza específica e, no quarto ano, surgem as disciplinas de natureza pedagógica. Embora esse formato de curso, oficialmente, não exista mais, a herança da origem, implicitamente, determina uma forte predominância dos conteúdos específicos em detrimento aos da área pedagógica nos cursos de licenciatura em Matemática. (POSTINGUE; PERALTA, 2018; POSTINGUE, 2019).

O referido modelo de formação inicial docente talvez ainda esteja presente nas licenciaturas e, como já apontava, na década de noventa do século XX, Pereira (1999), a racionalidade técnica presente nos currículos de formação de professores tem-se mostrado inadequada às demandas da realidade da prática profissional docente atual. Além da ênfase em teoria, nesta concepção acredita-se que basta o conhecimento específico de matemática a quem vai ensinar. Esse mesmo autor afirma que esse tipo de formação não foi superado, principalmente pela departamentalização, que gera segmentação, existente nas instituições de Ensino Superior, em que as disciplinas/áreas não se articulam.

Segundo Peralta (2019) e Postingue e Peralta (2018), propostas de superação da racionalidade técnica na formação de professores têm sido alvo de discussões fomentadas por resultados de pesquisas acadêmicas. Um dos referenciais que vem sendo usado para problematizar a formação de professores, segundo a racionalidade que a caracteriza, é a Teoria da Ação Comunicativa (HABERMAS, 2001).

Jürgen Habermas, sociólogo e filósofo expoente da Alemanha pós-guerra, desenvolveu uma teoria comunicacional defendendo que a interação entre os interlocutores sociais seja analisada segundo a racionalidade das relações que as subjazem. Ele consegue superar o pessimismo dos fundadores da Escola de Frankufurt, berço da Teoria Crítica, quanto às possibilidades de realização de um projeto de acordo com concepções iluministas e um conceito de ação voltado à defesa do potencial emancipatório da razão.

São quatro os tipos de ações descritas por Habermas (2001, 2002), a saber: I) a ação teleológica (um ator escolhe, entre diferentes alternativas, os melhores meios para conseguir um fim no mundo objetivo); II) a ação regulada por normas (os membros de um grupo social orientam suas ações segundo normas comuns do mundo social); III) a ação dramatúrgica (pessoas se comportam como se as outras fossem seu público, havendo a necessidade de cenificação, de construção de certa imagem); IV) a Ação Comunicativa (a interação ocorre por meio de discurso entre sujeitos capazes de linguagem e de ação, com fins de Entendimento). Em relação à forma de coordenação das ações entre falantes em um discurso num processo de interação social, Habermas admite duas formas de interação: estratégica e comunicativa. As relações entre ação e discurso podem se comportar de maneiras unicamente o êxito (Ação Estratégica) ou objetivando o Entendimento (Ação 
Comunicativa) (HABERMAS, 2002). Dentro dessa lógica, Habermas (2001; 2002; 2006) apresenta a racionalidade comunicativa em oposição à racionalidade instrumental em sua Teoria da Ação Comunicativa (TAC).

A Ação Estratégica busca influenciar os outros sujeitos do discurso de maneira a impor posições; ao passo que a Ação Comunicativa visa ser fonte de interação social com potencial consensual promovendo Entendimento. A Ação Comunicativa se pauta na simetria entre os que pretendam se entender.

As potencialidades da TAC são discutidas em produções acadêmicas que tem dela se utilizado para fundamentar investigações e reflexões acerca de uma prática docente capaz de considerar a interlocução entre sujeitos e vincular conhecimentos científicos e princípios éticos. (DEUTSCH, 2005; GONÇALVES, 1999; LONGHI, 2005; MEDEIROS, 2005; MÜHL, 1999; ORQUIZA de CARVALHO, 2005; PESCE, 2007; PINTO, 1994; PERALTA, 2012; 2019; POSTINGUE, 2019). A TAC se apoia no conceito de professor como protagonista em contextos de formação. $E$ tais contextos poderiam ser traduzidas em termos de ações que não se pautassem na racionalidade instrumental. Racionalidade essa fundamentada em políticas públicas elaboradas de acordo com interesses estatais e mercadológicos, de tal forma que "o mercado de trabalho assume, então, finalidade última da formação de professores, desconsiderando, por exemplo, que todo e qualquer processo formativo é, acima de tudo, um processo de constituição histórica do indivíduo" (MEDEIROS, 2005, p. 199).

A pesquisa de Gatti e Nunes (2009), ao analisar os currículos dos cursos de Licenciaturas em Letras, Ciências Biológicas e Matemática, escolhidas por serem as áreas com maior carga horária na Educação Básica, constatou um cenário complexo no qual a formação de professores está inserida. Há muitos dilemas que a formação de professores precisa discutir, compreender e, se entender necessário, superar. E dentre eles podemos destacar a formação para o uso de tecnologias digitais que pode ser caracterizada como demanda urgente para a sociedade atual.

\section{A CONSTITUIÇÃO DOS DADOS}

A pesquisa objeto de investigação deste artigo se define, metodologicamente, como análise documental qualitativa, no qual foi realizada uma busca e análise de fontes documentais oriundas dos projetos pedagógicos de cursos de licenciaturas em matemática das três maiores universidades públicas do estado de São Paulo (UNESP, UNICAMP, USP).

A abordagem qualitativa documental é aquela que se caracteriza pela busca de documentos como fonte de dados, trilhando uma trajetória de descrição e análises. $\mathrm{Na}$ análise documental, o caminho que se dá entre a seleção dos documentos - que se entende pelas realizações produzidas pelo homem, traduzidas em materiais cientificamente autênticos - até a comunicação com os resultados, constitui um processo sistemático, inovador e coerente. (SILVA et. al., 2009). Para o desenvolvimento da pesquisa, foi utilizado o seguinte procedimento metodológico:

Primeiramente, foram mapeados todos os cursos de licenciatura, a instituição onde cada um é desenvolvido e em seguida o levantamento dos Projetos PolíticoPedagógicos (PPP) ${ }^{4}$, disponíveis nos sites dos cursos investigados, bem como 
Ementas e Planos de Ensino das disciplinas. Realizou-se uma análise qualitativa de algumas características descritas, concentrando ênfase em: ações e práticas que possam caracterizar a formação do futuro professor de matemática para o uso de tecnologias digitais; estrutura do conjunto de disciplinas suas Ementa se Planos de Ensino; se os saberes relacionados a tecnologias digitais para o ensino estão presentes. Finalmente, foi analisado a organização dos currículos e caracterização quanto as ações formativas para o uso de tecnologias digitais pelo futuro professor, segundo a racionalidade que as orientam, comunicativa ou instrumental. Ressaltamos que os Planos de Ensino foram os principais elementos de análise, afinal neles constam as propostas de intenções e ações que, ao serem descritas, revelam o tipo dessas ações, a coordenação das ações orientadoras dos discursos envolvidos e a racionalidade empregada.

\section{ALGUNS RESULTADOS: ALGUMAS DESCRIÇÕES E CONSIDERAÇÕES²}

Foram encontrados nove institutos ou faculdades, dentro da UNESP, UNICAMP e USP que oferecem o curso de licenciatura em matemática, que estão dispostos no Quadro 01 a seguir:

Quadro 1 - Instituição, localidade e disciplinas relacionadas ao uso de tecnologias digitais

\begin{tabular}{|c|c|c|c|}
\hline Instituição & Localidade & Disciplinas encontradas & $\mathrm{CH}$ \\
\hline \multirow{2}{*}{$\begin{array}{l}\text { UNESP - Faculdade de } \\
\text { Engenharia }\end{array}$} & \multirow[b]{2}{*}{ Ilha Solteira } & $\begin{array}{c}\text { Novas Tecnologias Aplicadas ao } \\
\text { Ensino de Matemática }\end{array}$ & $60 \mathrm{~h}$ \\
\hline & & $\begin{array}{l}\text { Introdução à Ciência da } \\
\text { Computação e Tecnologias } \\
\text { Interativas }\end{array}$ & $60 \mathrm{~h}$ \\
\hline \multirow{2}{*}{$\begin{array}{l}\text { UNESP - Faculdade de } \\
\text { Ciência e Tecnologia }\end{array}$} & \multirow{2}{*}{$\begin{array}{l}\text { Presidente } \\
\text { Prudente }\end{array}$} & Computação Simbólica & $60 \mathrm{~h}$ \\
\hline & & $\begin{array}{l}\text { Informática do Ensino da } \\
\text { Matemática }\end{array}$ & $60 \mathrm{~h}$ \\
\hline \multirow[b]{2}{*}{$\begin{array}{l}\text { UNESP - Faculdade de } \\
\text { Ciência }\end{array}$} & \multirow[b]{2}{*}{ Bauru } & $\begin{array}{l}\text { Lógica Matemática e } \\
\text { Computacional }\end{array}$ & $60 \mathrm{~h}$ \\
\hline & & $\begin{array}{l}\text { Tecnologias Digitais de } \\
\text { Informação e Comunicação em } \\
\text { Educação Matemática }\end{array}$ & $60 \mathrm{~h}$ \\
\hline \multirow{2}{*}{$\begin{array}{c}\text { UNESP - Instituto de } \\
\text { Geociências e Ciências } \\
\text { Exatas }\end{array}$} & \multirow{2}{*}{ Rio Claro } & $\begin{array}{l}\text { Introdução a Ciência da } \\
\text { Computação }\end{array}$ & $60 \mathrm{~h}$ \\
\hline & & $\begin{array}{l}\text { Tecnologia no Ensino de } \\
\text { Matemática }\end{array}$ & $60 \mathrm{~h}$ \\
\hline \multirow{2}{*}{$\begin{array}{l}\text { UNESP - Instituto de } \\
\text { Biociências, Letras e } \\
\text { Ciências Exatas }\end{array}$} & \multirow{2}{*}{$\begin{array}{l}\text { São José do Rio } \\
\text { Preto }\end{array}$} & $\begin{array}{l}\text { Introdução à Ciência da } \\
\text { Educação }\end{array}$ & $60 \mathrm{~h}$ \\
\hline & & $\begin{array}{l}\text { Informática no Ensino de } \\
\text { Matemática }\end{array}$ & $60 \mathrm{~h}$ \\
\hline \multirow{2}{*}{$\begin{array}{l}\text { UNESP - Faculdade de } \\
\text { Engenharia }\end{array}$} & \multirow{2}{*}{ Guaratinguetá } & Cálculo Numérico & $60 \mathrm{~h}$ \\
\hline & & Programação de Computadores & $60 \mathrm{~h}$ \\
\hline $\begin{array}{l}\text { UNICAMP - Instituto de } \\
\text { Matemática, Estatística } \\
\text { e Computação Científica }\end{array}$ & Campinas & $\begin{array}{l}\text { Recursos Computacionais no } \\
\text { Ensino de Matemática }\end{array}$ & ---- \\
\hline
\end{tabular}




\begin{tabular}{|c|c|c|c|}
\hline $\begin{array}{c}\text { USP - Instituto de } \\
\text { Matemática e } \\
\text { Estatística }\end{array}$ & São Paulo & Introdução à Computação & $60 \mathrm{~h}$ \\
\hline $\begin{array}{c}\text { USP - Instituto de } \\
\text { Ciências Matemáticas e } \\
\text { de Computação }\end{array}$ & São Carlos & $\begin{array}{c}\text { Introdução à Programação de } \\
\text { Computadores }\end{array}$ & $60 \mathrm{~h}$ \\
\hline
\end{tabular}

Fonte: Elaborado pelos autores (2016).

Os dados mostram que os cursos de licenciatura em matemática das instituições pesquisadas, de forma geral, possuem disciplinas ligadas ao uso de tecnologias. No entanto, essas disciplinas, acabam se restringindo ao uso de computadores, ou seja, os licenciando usam o computador, mas não há registros nas ementas acerca de formar para práticas relacionadas à educação com tecnologia, tecnologias digitais aplicadas à educação, uso de tecnologias digitais, uso de tecnologias com finalidades educacionais e/ou algo que relacione o trinômio educação - tecnologias digitais- ensino de matemática.

Os tópicos a seguir descrevem os dados encontrados para cada um dos cursos, enfatizando, a partir dos PPP dispostos nos sites disponíveis para consulta púbica, evidências que não registrem apenas o uso de computadores, mas que, via principalmente Planos de Ensino das disciplinas, sinalizem o compromisso de vincular tecnologias digitais ao ensino de matemática, propondo formar futuros professores para tal.

\section{a) UNESP - Faculdade de Engenharia de llha Solteira}

O Projeto Político Pedagógico (PPP) encontrado no site da Unesp - FEIS estava desatualizado, então fora contatado o coordenador de curso, que encaminhou uma versão mais recente do documento.

A carga horária total para o curso é de 2820 horas e, deste total, 855 horas são dedicados aos componentes de formação didático-pedagógica, ou seja, mais de $30 \%$ da carga horária total, distribuídas da seguinte forma: 420 horas de Prática como Componente Curricular (PCC), 375 horas de formação pedagógica e 60 horas de Oficinas Pedagógicas desenvolvidas como Atividades Acadêmico-CientíficoCulturais.

O PPP analisado discorre sobre os projetos mantidos por parcerias com as escolas públicas municipais e estaduais de llha Solteira. Dentre os projetos presentes no PPP, três deles são na área de tecnologia aplicada à Educação. Abaixo esses três projetos descritos, retirados do Projeto Político Pedagógico de Alteração Curricular do Curso de Licenciatura em Matemática da Faculdade de Engenharia UNESP - Campus de Ilha Solteira. São eles:

- Tecnologia Aplicada à Educação (Unesp/Prefeitura Municipal de Ilha Solteira): Possibilita que os licenciandos da FEIS/UNESP vivenciem a prática didática em Laboratório Computacional;

- InterRobótica: Robótica Interdisciplinar na Escola (Unesp/Proex): Tem como objetivo implementar oficinas semanais de robótica, desenvolvendo uma série de atividades pedagógicas interdisciplinares, experimentais e de natureza inovadoras, relativas aos principais conceitos científicos tratados na Educação Básica; 
- Desenvolvimento de Tecnologias Assistivas para o uso do Computador e Apoio Pedagógico para estudantes com Necessidades Educacionais Especiais (Unesp/Proex): O projeto é constituído de atividades diversificadas que envolvem conhecimentos diferenciados, como a confecção de material digital e vivências e aplicações de metodologias de ensino para educação especial, contribuindo para a aprendizagem de pessoas com deficiências.

Além dos projetos acima, encontrou-se duas disciplinas, presentes na matriz curricular, destinadas ao ensino do uso de tecnologias e cujos Planos de Ensino foram analisados, sendo elas: Novas Tecnologias Aplicadas ao Ensino de Matemática e Introdução à Ciência da Computação e às Tecnologias Interativas.

A disciplina Novas Tecnologias Aplicadas ao Ensino de Matemática é prevista para ser realizada no segundo semestre do quarto ano do curso, possui carga horaria de 60 créditos e acompanha a seguinte Ementa: A integração de linguagem multimídia no currículo de matemática da educação básica: caracterização, usos consolidados e desafios. Avaliação de softwares educacionais para a educação matemática: principais usos em sala de aula e novas possibilidades de aplicações. Tecnologias interativas como ferramentas para a educação matemática: ferramentas Web, ambientes virtuais para educação a distância. A educação matemática com programação e robótica. Ferramentas tecnológicas de conteúdo específico: Sistemas de computação algébrica simbólica; ambientes de geometria dinâmica; applets interativos. Na carga horária destinada à Prática como Componente Curricular será abordada a utilização e discussão das novas tecnologias no ensino e na aprendizagem da matemática.

Já na disciplina Introdução à Ciência da Computação e Tecnologias Interativas estão previstas para o primeiro semestre do primeiro ano, possui carga horária de 60 créditos e acompanha a seguinte Ementa: Conceitos Básicos de Computadores. Aplicativos Básicos para Expressão Multimídia, Apresentação de Informação e Manipulação de Dados. Algoritmos: Desenvolvimento conceitual de algoritmos. Linguagem Algorítmica Estruturada. Introdução à Linguagem de Programação. Aplicação de Algoritmos na resolução de problemas matemáticos. Ferramentas tecnológicas de colaboração e comunicação de mídia digital baseado na Web. Além disso percebe-se que quase $70 \%$ da carga horária das disciplinas são destinadas a disciplinas de conteúdo específico matemático.

Essas duas se destinam à formação do professor de matemática para o uso de tecnologias digitais, uma está prevista para o primeiro semestre do primeiro ano, enquanto a outra está prevista para o segundo semestre do quarto ano, mostrando assim uma distância entre elas. A disciplina Iniciação à Ciência da Computação e Tecnologias Interativas possui sua carga horária dividida entre teoria e prática e não prevê espaço para que o licenciando argumente, discuta, exponha e reflita sobre seu aprendizado e própria experiência. Já a disciplina Novas Tecnologias Aplicadas ao Ensino de Matemática possui 50\% de sua carga horária destinada a parte teórica e o restante para as PCC que busca uma postura reflexiva do licenciando. No entanto, não prevê espaço para discussões, interação e debates públicos. Aparentemente, mesmo declarando compromisso com a formação do futuro professor, a racionalidade empregada não prescinde de uma natureza instrumental com processos (ensino -aprendizagem/aprendizagem-aplicação) unidirecionais. 


\section{b) UNESP - Faculdade de Ciências e Tecnologia de Presidente Prudente}

No site da UNESP - Campus de Presidente Prudente, não estava disponível o PPP do curso, assim sendo, foi solicitado ao coordenador do curso que forneceu o documento atualizado.

Dentre os diversos laboratórios descritos no documento analisado, cinco deles são destinados ao uso de tecnologias, sendo eles: Laboratório Didático de Computação; Laboratório do Centro de Promoção para Inclusão Digital, Educacional e Social; Laboratório Didático de Informática; Laboratório de Tecnologia e Educação; Laboratórios Didáticos de Computação. Além desses laboratórios existem duas disciplinas na matriz curricular, cujos Planos de Ensino foram analisados, que abrangem o uso de tecnologias, sendo elas: Computação Simbólica e Informática no Ensino da Matemática.

A disciplina Computação Simbólica é prevista para ser realizada no primeiro semestre do segundo ano do curso, possui carga horaria de 60 créditos e acompanha a seguinte Ementa: Noções gerais sobre computadores: histórico, unidades funcionais e arquitetura básica e princípio de funcionamento. Algoritmos e lógica de programação: conceito, exemplos, formas de representação de algoritmos; estruturas de controle de atribuição, seleção e repetição. Softwares de computação algébrica: visão geral sobre os sistemas existentes, características e propósito; funcionalidades, recursos matemáticos e gráficos disponíveis. Matlab: ambiente do Matlab (Interface de trabalho); recursos básicos; conceito de variáveis; funções de entrada e saída; arquivos de comandos; estruturas de controle no Matlab; matrizes; armazenamento, acesso, operações fundamentais e matrizes esparsas; exemplos explorando manipulação de conjuntos, arranjos uni e bidimensional; polinômios; gerenciamento de arquivos; gráficos bidimensionais e tridimensionais.

Já a disciplina Informática no Ensino da Matemática está prevista para ser realizada no segundo semestre do quarto ano, possui carga horária de 60 horas e acompanha a seguinte Ementa: História da informática educativa. As tecnologias da informação e comunicação (TIC) no processo ensino e aprendizagem de matemática: abordagem instrucionista; abordagem construcionista: o computador como ferramenta para resolver situações-problema; o ciclo descrição-execuçãoreflexão-depuração. Softwares matemáticos: exploração, análise e uso de softwares matemáticos: jogos, tutorias, exercício e prática, linguagem de programação logo e simulação; a Internet como recurso pedagógico. A mediação pedagógica e o uso da tecnologia: projetos de trabalho.

A disciplina Computação Simbólica não prevê em sua Ementa e no Plano de Ensino espaço destinado a discussão, argumentação e/ou momentos que possibilitem a interação entre os licenciandos no decorrer da disciplina, mostrando assim que a racionalidade presente é uma racionalidade técnica. Em contrapartida, a disciplina Informática no Ensino de Matemática prevê em seu plano de aula momentos de discussão e sistematização das leituras indicadas, assim como a reflexão sobre o papel do professor que atua em ambientes enriquecidos pela tecnologia, dessa forma a racionalidade presente nesta disciplina se distancia daquela meramente instrumental. As atividades descritas se aproximam de características do Agir Comunicativo. A carga horária do curso é de 3030 horas sendo que 915 horas são de disciplinas didáticos pedagógicas, incluindo as disciplinas didáticas pedagógicas optativas. 


\section{c) UNESP - Faculdade de Ciências de Bauru}

O PPP do curso de Licenciatura em Matemática UNESP - Campus Bauru foi acessado pelo site da universidade, onde foram localizados os Planos de Ensino de cada disciplina.

Existem duas disciplinas na grade curricular que trabalham o uso de tecnologias: Lógica Matemática e Computacional; Tecnologias Digitais de Informação e Comunicação em Educação Matemática. Além dessas disciplinas existe o Laboratório Didático de Matemática (LDM) que possui uma sala de Tecnologia Informáticas.

A disciplina Lógica Matemática e Computacional está prevista para ser realizada no primeiro semestre do segundo ano, possui carga horária de 60 horas e acompanha a seguinte Ementa: Lógica proposicional, lógica quantificacional, dedução - Conceitos básicos sobre computadores e sua programação - Construção de algoritmos usando técnicas de programação - Estruturas básicas de programação. O Plano de Ensino não prevê horários e ambientes para discussão, não está previsto que o licenciando possa fazer alguma intervenção ou mudança no decorrer da disciplina através do discurso, mostrando uma orientação de ações próxima da racionalidade técnica, onde, aparentemente, pelo Plano, o professor não evitará o modelo de aulas expositivas amparado em resolução de exercícios.

Já a disciplina Tecnologias Digitais de Informação e Comunicação em Educação Matemática está prevista para ser cursada no segundo semestre do terceiro ano, possui carga horária de 60 horas e acompanha a seguinte Ementa: Caracterização das Tecnologias Digitais de Informação e Comunicação (TDIC) na Educação. Integração das TDIC na Educação Matemática, Possibilidades da modalidade de Educação a Distância (EaD). - Análise de materiais didáticos referente ao uso de TDIC nos anos finais do Ensino Fundamental e do Ensino Médio. - Elaboração de atividades voltadas à prática nos Ensinos Fundamental II e Médio, abordando os conteúdos matemáticos, utilizando-se das TIDC. O Plano de Ensino prevê o estudo de textos e discussões a respeito dos mesmos, no entanto não fica claro se as discussões oportunizarão ao licenciando oportunidade de fazer uso de atos discutir apoiado em racionalidades que não a instrumental.

\section{d) UNESP - Instituto de Geociências e Ciências Exatas de Rio Claro}

O PPP, a matriz curricular e as Ementas encontradas no site da UNESP Campus Rio Claro estavam desatualizados, porém, fora solicitado ao coordenador do curso que forneceu uma versão mais recente.

No Instituto de Geociências e Ciências Exatas de Rio Claro o estudante pode optar entre duas modalidades para sua formação: licenciatura ou bacharelado. Caso o estudante opte pela licenciatura, o curso possui 3030 horas, sendo 2820 horas referentes às disciplinas obrigatórias e optativas (englobando 505 horas de prática como componente curricular) e 210 horas referentes às atividades acadêmico-científico culturais.

As disciplinas destinadas ao uso de tecnologia digital são Introdução à Ciência da Computação e Tecnologia no Ensino de Matemática. A disciplina Introdução à Ciência da Computação I está prevista para ser realizada no segundo semestre do primeiro ano, possui carga horária de 60 horas e acompanha a seguinte Ementa: Conceitos básicos sobre computadores e sua programação. Construção de 
algoritmos, usando técnicas de programação estruturada. Estruturas básicas de programação. Subprogramas. Tipos de dados estruturados homogêneos. Manipulação de arquivos. O PPP não disponibiliza os Planos de Ensino de cada disciplina e também não prevê um ambiente onde atividades possam potencializar ações que se orientem por razão comunicativa (espaços de discussão, debates, argumentações, associações livres, constituição de esfera públicas).

A disciplina Tecnologia no Ensino de Matemática está prevista para ser realizada no segundo semestre do quarto ano, possui carga horária de 60 horas, sendo que 30 horas são teóricas e o restante dedicadas a Prática como Componente Curricular e acompanha a seguinte Ementa: Noções gerais sobre computadores e mídias digitais. Softwares para o estudo de funções matemáticas. O uso de tecnologias para o ensino de Matemática na educação básica. Softwares com recurso de acessibilidade para estudantes com necessidades educacionais especiais. Tecnologia da informação e comunicação e processos de pensamento. Diferentes abordagens metodológicas para as tecnologias digitais. Tecnologia da informação e comunicação e formação docente. Também não tivemos acesso ao Plano de Ensino dessa disciplina e sua Ementa não prevê nenhum espaço ou oportunidade para a Ação Comunicativa ser potencialmente estruturada, caracterizando assim uma aproximação à racionalidade instrumental.

e) UNESP - Instituto de Biociências, Letras e Ciências Exatas de São José do Rio Preto

Atualmente, a UNESP - Campus de Rio Preto oferece o curso de Licenciatura em Matemática nos períodos diurno e noturno. Infelizmente, o PPP atualizado ainda não estava disponível, entramos em contato com a coordenação que nos enviou uma versão mais atualizada com os Planos de Ensino.

Das disciplinas observadas, três declaram vincular a formação do futuro professor para o uso de tecnologias em sala de aula: Introdução a Ciência da Computação; Informática no Ensino de Matemática e Recursos Computacionais no Ensino de Matemática.

A disciplina Introdução a Ciência da Computação está prevista para ser realizada no primeiro ano de curso, possui carga horária de 60 horas tanto no período diurno como noturno e acompanha a seguinte Ementa: 1. Conceitos básicos sobre os computadores e sua programação. 2. Construção de algoritmos usando técnicas de programação estruturada. 3. Estruturas básicas de programação. 4. Subprogramas. 5. Tipos de dados estruturados homogêneos. 6. Prática Pedagógica / Prática como Componente Curricular.

A disciplina Informática no Ensino de Matemática está prevista para ser realizada no quarto ano de curso, possui carga horária de 60 horas tanto no período diurno como noturno e acompanha a seguinte Ementa: 1. Análise e discussão dos PCN e Currículo do Estado de São Paulo no que se refere ao uso de tecnologia, em especial computadores/softwares, como recurso pedagógico no ensino de Matemática. 2. Utilização de softwares matemáticos adequados para se explorar/estudar conteúdos matemáticos. 3. Utilização de Jogos Virtuais visando o ensino-aprendizagem de Matemática. 4. Elaboração de roteiros de atividades, usando recursos de informática, a serem utilizados em aulas práticas em escolas do ensino básico para trabalhar conteúdos matemáticos. 5 . Utilização e análise de sites matemáticos para estudos e pesquisa. A disciplina Recursos Computacionais 
no Ensino de Matemática está prevista para ser realizada no terceiro ano de curso, possui carga horária de 60 horas tanto no período diurno como noturno e acompanha a seguinte Ementa: 1. Planilhas Eletrônicas. 2. Ambientes Gráficos. 3. Sistemas de Computação Algébrica e Simbólica. 4. Ensino à Distância. 5. Pesquisas Eletrônicas, Processadores de Texto e Hipertexto. 6. Critérios para Seleção de Recursos Computacionais no Ensino de Matemática.

Os Planos de Ensino das disciplinas não estavam disponíveis, o que impediu, somente pelas Ementas e demais descrições no documento do PP, evidenciar indícios de aproximações a práticas orientados ao de Agir Comunicativo.

\section{f) UNESP - Faculdade de Engenharia de Guaratinguetá}

O PPP da UNESP - Campus de Guaratinguetá não estava disponível no site, no entanto a coordenação do curso, após solicitação, disponibilizou uma versão resumida da atualização mais recente.

O curso tem carga horária de 2865 horas, distribuídos em eixos: Eixo 1: Conhecimento matemático - 960h; Eixo 2: Conhecimento das Ciências Afins 240h; Eixo 3: Conhecimento de Informática - 120h; Eixo 4: Conhecimento Pedagógico e de Educação Matemática - 870h; Eixo 5: Conhecimento de Comunicação e Expressão - 60h.

As disciplinas relacionadas ao uso de tecnologia são Programação de Computadores e Cálculo Numérico, no entanto essas disciplinas não estão relacionadas a utilizar a tecnologia como ferramenta de ensino, mas sim como recurso de resolução de problemas vinculados aos conteúdos da disciplina. A disciplina de Cálculo Numérico está prevista para ser realizada no primeiro semestre do primeiro ano, possui carga horária de 60 horas e acompanha a seguinte Ementa: Cálculo Diferencial e Integral I e Programação de Computadores Aritmética computacional. Solução de equações não lineares. Sistemas de equações lineares. Interpolação. Aproximação de funções (regressão). Integração Numérica. Equações diferenciais ordinárias. A versão do PPP analisada não traz o Plano de Ensino e a Ementa apenas traz o conteúdo que deve ser ministrado no decorrer da disciplina.

A disciplina Programação de Computadores está prevista para ser realizada no segundo semestre do primeiro ano, possui carga horária de 60 horas e acompanha a seguinte Ementa: Fundamentos de programação. Algoritmos e Fluxogramas. Conceitos básicos de programação. Estruturas de seleção. Estruturas de repetição. Estruturas de dados. Manipulação de arquivos. Essa disciplina está na mesma situação da disciplina de Cálculo Numérico e com isso não foi possível afirmar quão próximos ou distantes, os processos formativos empregados nas duas disciplinas, estão da Ação Comunicativa.

\section{g) UNICAMP - Instituto de Matemática, Estatística e Computação Científica}

Não encontramos no site do Instituto informações a respeito do PPP, apenas a matriz curricular com as Ementas. Apesar da tentativa de contato, não foi obtido respostas da coordenação e nem do departamento responsável pelo curso.

A partir das informações disponíveis fora levantada a disciplina Recursos Computacionais no Ensino de Matemática, destinada à formação do licenciando para o uso de tecnologias aplicadas ao ensino. Essa disciplina está prevista para ser realizada no segundo semestre do primeiro ano e acompanha a seguinte Ementa: 
Análise de aplicativos de informática para o ensino-aprendizagem de matemática na educação básica. Sistemas de computação algébrica e simbólica. Ambientes de geometria dinâmica. Processadores de textos matemáticos e científicos. Resolução de problemas em situações de ensino envolvendo, por exemplo, sistemas lineares, equações polinomiais, geometria analítica e funções de uma variável.

\section{h) USP - Instituto de Matemática e Estatística de São Carlos}

O PPP do curso disponível no site da instituição estava desatualizado e apesar da tentativa de contato com a coordenação do curso, não obtivemos acesso a versão mais atualizada. São oferecidos dois cursos de Licenciatura em Matemática por esta instituição, um diurno e outro noturno. No site é possível encontrar a matriz curricular e os códigos de cada disciplina. A cada disciplina está associado um link que nos encaminha para o Plano de Ensino de cada disciplina, contendo o programa resumido. No entanto, em algumas disciplinas faltavam Ementa e os objetivos.

A disciplina que prevê o uso de tecnologia para a formação dos professores é Introdução à Computação que está prevista para ser realizada no terceiro semestre de curso do período diurno e no quarto semestre de curso do período noturno, com carga horária de 60 horas e acompanha a seguinte Ementa: Números inteiros: apresentação axiomática; axioma de indução finita e princípio do menor inteiro: aplicações, divisibilidade, Anel dos polinômios com coeficientes racionais, algoritmo da divisão, polinômios irredutíveis, Lema de Gauss e Critérios de Eisenstein. Congruências, Equações diofantinas lineares, Teorema chinês do resto; Teoremas de Fermat, Euler e Wilson. A partir da versão enxuta de Plano de Ensino disponível não foi possível identificar espaços e/ou processos formativos que oportunizem ao licenciando uso de atos de fala, ser a gente ativo argumentativo no decorrer do curso. Não foi possível ainda caracterizar o tipo de razão empregada nas intenções e ações a serem desenvolvidas.

\section{i) USP - Instituto de Ciências Matemáticas e de Computação de São Paulo}

A análise do PPP do curso no site da USP - Campus de São Paulo, bem como a matriz curricular apontou uma disciplina que relacionava tecnologia digital e ensino de matemática. A disciplina é Introdução à Programação de Computadores que está prevista para ser realizada no primeiro semestre de curso, com carga horária de 60 horas e acompanha a seguinte Ementa: Conceitos básicos sobre computadores, algoritmos, linguagens e programas. Aplicações numéricas e não numéricas. Prática de programação em linguagem C. O Plano de Ensino não evidencia caraterísticas de práticas que se aproximam de racionalidade alternativa à racionalidade instrumental e nem que se oriente para formar para o uso de tecnologias digitais no/para ensino de matemática.

\section{CONSIDERAÇÕES FINAIS}

O trabalho que consistia em mapear os cursos de Licenciatura em Matemática das universidades públicas do estado de São Paulo - USP, UNICAMP e UNESP, encontrando os seus respectivos Projetos Políticos Pedagógicos, mostrou-se mais difícil do que o esperado. A busca pelos documentos citados muitas vezes não deu resultado e em outras vezes, rendeu documentos desatualizados. Dessa forma, 
tivemos que fazer contato com coordenadores de curso ou com o departamento, sendo que em alguns campi não tivemos resposta.

Uma justificativa para alguns cursos não disponibilizarem os PPP solicitados foi o fato de os cursos estarem passando por reestruturações curriculares. A investigação caminhou com o material que fora possível acessar e o inicio da análise dos PPP levantados já se deparou com um outro desafio: a diferença e desigualdade nos documentos que constavam os PPP. Fora encontrada uma grande variedade de estrutura, volume e nível de detalhamento das informações que constituíam os PPP e davam forma e conteúdo aos Planos de Ensino. Esses desafios, aliados à publicidade parcial da documentação, acabam por se configurar em obstáculo para estudos curriculares que enfatizem cursos de graduação nas universidades púbicas do estado de São Paulo.

A partir dos dados constituídos é possível observar que os cursos, de forma geral, possuem alguma(s) disciplina(s) ligada(s) ao uso de tecnologia digital. No entanto, algumas delas acabam se restringindo ao uso de computadores como ferramentas ou recursos didáticos para o desenvolvimento dos conteúdos das disciplinas, sem, necessariamente, o compromisso com práticas e/ou processos de formação dos futuros professores para o uso de tecnologias digitais no exercício da docência para o ensino de matemática. Isto posto, pois ainda que não possamos afirmar que na dinâmica cotidiana dos cursos ocorram ou não momentos formativos orientados para a referida formação, a existência ou a ausência de evidências explícitas podem ser sinalizadoras em termos de escolhas, prioridades e conceitos envolvidos nos currículos investigados.

Outro ponto a ser observado é que, dentre os cursos que disponibilizaram as cargas horárias e possibilitaram estabelecer relação entre elas, o total de créditos/horas das disciplinas de conhecimentos específicos de/em matemática é superior ao daquelas de/em conhecimentos pedagógicos. Ainda que esse debate (disciplinas específicas $x$ disciplinas pedagógicas) seja relativamente antigo e possa ser considerado "ultrapassado", a atualidade desse dado é incontestável: a promissora articulação dos conhecimentos nos currículos ainda não se concretizou. Tendo em conta desafios contemporâneos, a serem enfrentados pelo futuro professor, uma formação que não considere as necessidades formativas, e se estruture a partir de paradigmas de racionalidade que não a comunicativa, figura como pacto com a ação estratégia, sob a tutela da razão técnica, acarretando incertezas gerais quanto ao exercício da docência em contextos educacionais. 


\title{
TRAINING NEEDS OF MATHEMATICS TEACHER FOR THE USE OF DIGITAL TECNOLOGIES: A CURRICULAR ANALYSIS ACCORDING TO HABERMASIAN PRINCIPLES
}

\begin{abstract}
This research aimed to identify characteristics of teacher education for the use of digital technologies in the teaching of curricular contents in the curriculum of Political Pedagogical Projects of a degree in mathematics of public universities of the state of São Paulo (UNESP, UNICAMP, USP). Guided by the qualitative documentary analysis, it is intended to provide information about the curricular organization of undergraduate courses in mathematics, the characteristics of the curricula of these courses in relation to the training for the use of digital technologies in the classroom, the predominance of the workload of the subjects related to the specific knowledge in mathematics to the detriment of the knowledge regarding the fundamentals of education, the training for teaching and digital technologies as a resource to pedagogical practice.
\end{abstract}

KEYWORDS: Teacher Training. Curriculum. Degree in Mathematics. Digital Technologies. 
1 Pesquisa realizada com apoio da Fundação de Amparo à Pesquisa do Estado de S. Paulo - FAPESP - Processo 2015/26166-8.

2 A Universidade Virtual do Estado de São Paulo (UNIVESP) apesar de ser uma universidade estadual e oferecer cursos de licenciatura em matemática, o faz na modalidade à distância e não presencial. Por isso, não foi objeto da pesquisa relatada.

3 Os termos com carga conceitual em Habermas serão abordados com letra maiúscula, como Entendimento, Emancipação, Ação Estratégica e Ação Comunicativa, a menos que se tratarem de citação literal.

4 Devido a mudanças nas Diretrizes Curriculares para a Formação de Docentes para a Educação Básica, alguns dos cursos analisados estavam passando por estruturação e os PPP que estavam disponíveis no site eram versões, possivelmente, desatualizadas.

\section{REFERÊNCIAS}

DEUTSCH, R. J. Ciências, ética e ação comunicativa: a prática pedagógica realizada no contexto da escola. Universidade do Vale do Rio dos Sinos. Tese (doutorado em educação). São Leopoldo: UNISINOS, 2005.

GIORGI, C. A. G. et al. Necessidades formativas de professores de redes municipais: contribuições para a formação de professores crítico-reflexivo. São Paulo: Cultura Acadêmica -SciELO-Editora UNESP, 2010.

GATTI, B. A.; NUNES, M. M. (org). Formação de professores para o ensino fundamental: estudo de currículos das licenciaturas em pedagogia, língua portuguesa, matemática e ciências biológicas. v. 29; São Paulo: Fundação Carlos Chagas, 2009.

GONÇALVES, M. A. S. Teoria da ação comunicativa de Habermas: possibilidades de uma ação educativa de cunho interdisciplinar na escola. Educação e Sociedade, Campinas, ano XX, n. 6, p. 125-140, abr. 1999.

GRINSPUN, M. P. S. Z. Educação Tecnológica. In: GRINSPUN, M. P. S. Z. (Org.) Educação Tecnológica: desafios e perspectivas. São Paulo, Ed. Cortez, 1999.

GUIMARÃES, Y. A. F. Identidade Curricular na Formação Inicial de Professores de Física. 2014. n. 511 f. Tese (Doutorado em Ensino de Ciências) - Universidade de São Paulo, São Paulo, 2014. 
HABERMAS, J. Acções, actos de fala, interacções linguisticamente mediadas e o mundo vivo. In HABERMAS, J. Racionalidade e comunicação. Lisboa: Edições 70, 2002.

HABERMAS, J. Teoría de la acción comunicativa I: racionalidad de la acción y racionalización social. 3a ed. Madri: Taurus, 2001.

HABERMAS, J. Técnica e ciência como “ideologia”. Lisboa: Edições 70, 2006.

LOPES, A. C. Políticas de currículo: questões teórico-metodológicas. In: LOPES, A. C.; DIAS, R. E.; ABREU, R. (Org.). Discursos nas políticas de currículo. Rio de Janeiro: Quartet Editora / Faperj, p. 19-44, 2011.

LONGHI, A. J. A ação educativa na perspectiva da teoria do agir comunicativo de Jürgen Habermas: uma abordagem reflexiva. Tese (doutorado em Educação). Universidade Estadual de Campinas. Campinas: UNICAMP, 2005.

MARX, K. O capital: crítica da Economia Política. Livro I, Vol. I, 1988

MEDEIROS, A. S. Formação de professores sob a perspectiva da teoria crítica e das políticas educacionais. Educação e Linguagem, São Paulo, ano 8, n. 11, p. 195-210, jan.-jun. 2005.

MÜHL, E. H. Racionalidade comunicativa e educação emancipadora.

Universidade Estadual de Campinas, Tese de doutorado. Campinas, 1999.

ORQUIZA-DE-CARVALHO, L. M. A educação de professores como formação cultural: a constituição de um espaço de formação na interface entre a universidade e a escola. UNESP; Tese de Livre- Docência. Ilha Solteira/SP, 2005.

PACHECO, J. Para a noção de transformação curricular. Cadernos de Pesquisa, v 46, n. 159, 64-77, 2016.

PAPERT, S.; RESNICK, M. Technological Fluency and the Representation of Knowledge. Proposal to the National Science Foundation. MIT MediaLab, 1995.

PERALTA, D. A; GUIMARÃES, E. C. Robotics at school as an interdisciplinary teaching approach in Basic Education: The future has arrived to school?. Brazilian Journal of Computers in Education, v. 26, n. 1, p. 30-50, 2018. 
PERALTA, D. A. Formação Continuada de Professores de Matemática em Contexto de Reforma Curricular: contribuições da Teoria da Ação Comunicativa. 2012. n. 208 f. Tese (Doutorado em Educação para Ciência). Universidade Estadual Paulista - UNESP, 2012.

PERALTA, D. A. Habermas e as professoras e professores de matemática: vislumbrando oásis. Curitiba: Editora Appris, 2019.

PEREIRA, J. E. D. As licenciaturas e as novas políticas educacionais para a formação docente. Educação \& Sociedade, ano XX, n. 68, p. 109-125, dez. 99.

PESCE, L. As contradições da institucionalização da educação a distância, pelo Estado, nas políticas de formação de educadores: resistência e superação. Revista HISTEDBR On-line, Campinas, n.26, p.183-208, jun. 2007.

PINTO, J. M. R. Administração e liberdade: um estudo do conselho de escola à luz da teoria da ação comunicativa de Jürgen Habermas. Tese (Doutorado em Eucação). Universidade Estadual de Campinas - UNICAMP, 1994.

PIRES, C. M. C.; Educação Matemática e sua influência no processo de organização e desenvolvimento curricular no Brasil. Revista Bolema, Rio Claro, SP, ano 21, n. 29, p. $13-42,2008$.

POSTINGUE, T. P. Formar para avaliar: racionalidade comunicativa e currículos de licenciatura em matemática. 2019. n. 184 f. Dissertação (Mestrado em Ensino e Processos Formativos). Universidade Estadual Paulista - UNESP, 2019.

POSTINGUE, T. P.; PERALTA, D. A. Avaliação da Aprendizagem como Elemento Curricular nas Licenciaturas em Matemática das Universidades Estaduais Paulistas: uma carência declarada. Perspectivas da Educação Matemática, v. 11, n. 27, p. 978-1001, 2018.

RODRIGUES, M. A. P. Análise de práticas e de necessidades de formação. Lisboa, Portugal: Direcção-Geral de Inovação e Desenvolvimento Curricular, 2006.

SILVA, T. T, Documentos de identidade: uma introdução às teorias do currículo. Belo Horizonte: Autêntica, 2001.

SILVA, L. R. C. et al. Pesquisa documental: alternativa investigativa na formação docente. In: Congresso Nacional de Educação. 2009. p. 4554-4566. Disponível em: <http://educere.bruc.com.br/arquivo/pdf2009/3124 1712.pdf>. Acesso em: 30 mar. 2020. 
Recebido: 25 set. 2019.

Aprovado: 02 abr. 2020

DOI: $10.3895 /$ rbect.v13n3.10814

Como citar: GUIMARÃES, E. C.; POSTINGUE, T. P.; PERALTA, D. A. Necessidades formativas de

professores de matemática para o uso de tecnologias digitais: uma análise curricular segundo princípios

habermasianos. Revista Brasileira de Ensino de Ciência e Tecnologia, Ponta Grossa, v.13, n. 3, p. 243

263, set./dez. 2020. Disponível em: <https://periodicos.utfpr.edu.br/rbect/article/view/10814>. Acesso em:

$\mathrm{XXX}$

Correspondência: Eduardo Cortez Guimarães - eduardocortez34@gmail.com

Direito autoral: Este artigo está licenciado sob os termos da Licença Creative Commons-Atribuição 4.0

Internacional.

(c) (1) 